\title{
Optimization of Distribution of the Fund of Evaluative Means When Forming the Universal Educational Actions
}

\author{
Novgorodtseva T.Yu. ${ }^{1}$, Pegasova N.A. ${ }^{2}$, Ivanova E.N. ${ }^{3}$, Nikiforova I.A. ${ }^{4} \&$ Azarenko A.A. ${ }^{5}$ \\ ${ }^{1}$ Ph.D. of Engineering Sciences, Associate Professor, Department of Informatics and Informatics Education Methods, \\ Irkutsk State University, Russia, Irkutsk. \\ ${ }^{2} \mathrm{Ph}$.D. in pedagogical sciences, Associate Professor, Department of Informatics and Informatics Education Methods, \\ Irkutsk State University, Russia, Irkutsk. \\ ${ }^{3} \mathrm{Ph}$. D. in pedagogical sciences, Head of Department of Informatics and Informatics Education Methods, Department \\ of Informatics and Informatics Education Methods, Irkutsk State University, Russia, Irkutsk. \\ ${ }^{4} \mathrm{Ph}$.D. of physical mathematics Sciences, Associate Professor, Department of Informatics and Informatics Education \\ Methods, Irkutsk State University, Russia, Irkutsk. \\ ${ }^{5}$ Teacher of Information Sciences at MAGEI “Angarsk’s lyceum No.1”, Russia, Angarsk \\ Correspondence: Novgorodtseva T.Yu., Ph.D. of Engineering Sciences, Associate Professor, Department of \\ Informatics and Informatics Education Methods, Irkutsk State University, Russia, Irkutsk.
}

Received: February 22, 2020

Accepted: March 25, 2020

Online Published: March 26, 2020

doi:10.5430/ijhe.v9n3p190

URL: https://doi.org/10.5430/ijhe.v9n3p190

\begin{abstract}
The actuality of this research is determined by the acceptance of standards where a new sense of a concept "educational results" is given. Thus, a necessity to evaluate subject, cross-curriculum and personal results of students appears. The ways to evaluate the level of organization of the universal educational actions are reflected in the educational programs on each subject and in the programs of extracurricular activities. The FEM are worked out to monitor and check students' educational achievements with the requirements of the basic educational program in accordance with the requirements of standards.
\end{abstract}

Keywords: optimization model, educational results, evaluative means, method of experts' evaluation

\section{Introduction}

The introduction of the Federal State Educational Standards (the FSES) at the federal level and the transition of educational institutions to educational programs that meet the requirements of the standard is a comprehensive and multidimensional process.

According to the FSES two components are singled out in the structure of the basic educational program: planned results to master the basic educational program and a system for evaluation the achievement of the planned results to master the basic educational program. The planned results specify and concretize the general content of a subject, intersubject and personal results of students (Laws of the Russian Federation).

Each separate discipline determines main possibilities to form the universal teaching actions (the UTA) depending on its content and ways to organize students' activity.

The universal teaching actions are presented as an entire system in which mutually-caused and interconnected types of activities are pointed out:

- Cognitive - generally educational and logical connected with solving a problem;

- Communicative - determine competence in a social sphere;

- Personal - provide motivational orientation;

- $\quad$ Regulative - determine the organization of activity (Asmolov et al., 2011 ; Laws of the Russian Federation).

The forming of the UTA is a systematic and purposeful process. It is fulfilled through all subject spheres and trough extracurricular activity.

The methods to evaluate the level of the UTA's formation are reflected in the educational programs for each subject 
and in the programs of extracurricular activity. The results of the UTA's learning are determined for each age category of students. They are important aspectswhen monitoring students' achievements.

In order to control and to check students' educational achievements with the requirements of a concrete and basic educational program in accordance with the requirements of the FSES, the funds of evaluative means (the FEM) are worked out to realize current and input evaluation, final andintermediate certification of students. The fund of evaluative means is a constituent part of a methodical supply of a quality evaluation system for development of the basic educational program (BEP). It is a partof educational and methodical complex (including program of work) of a corresponding subject (Pashkevich, 2018).

The FEM is a complex of control and evaluative means that are used to assess knowledge, skills and competences of students at different levels of their education and as well as to conduct final certification of students and to check a corresponding level of their achievements to the requirements of the FSES after completing a specific BEP and subject (Pashkevich, 2018).

The problem is in the fact that nowadays there are no methodical recommendations or approaches to the developing of the FEM in educational institutions approved legislatively because funds of evaluative means are worked out and approved by educational institution on its own (according to the FSES). Consequently, the working out of the FEM is a teacher's duty and as a rule this process happens intuitively. It is not guided by any methods and ways and it does not meet standard requirements.

This problem is not only in Russia, it is in the global community too. In the works (The Nation's Report Card, 2013; National Center for Education Statistics in the sphere of education, 2013; Agencia de Calidad de la Educaciónhttp, 2018; The National Assessment Program; 2018; My School, 2018), the present practice of organization and realizing national monitoring of the education quality are observed, the approaches to interpretation and giving the data of monitoring for different groups of users are shown, the peculiarities of using a test's results (used as an evaluative means) in Australia, the USA and Chile are pointed out.

The main peculiarity of the Australian monitoring NAPLAN is the use of a test's results to monitor progress of each child. The marking of all students of a certain age during several years of education let determine an individual dynamics of education of a certain student and let plan measures to develop individual trajectory of education at school level (The National Assessment Program; 2018; My School, 2018).

The peculiarity of monitoring in the USA (NAEP) is in that the results of testing become a foundation to discuss and to make solutions in the educational policy after publishing them in the open access (The Nation's Report Card, 2013; National Center for Education Statistics in the sphere of education, 2013). More than that, the government follows up a gap in educational achievements among students from different social and ethno-cultural groups. It is necessary to note that educational achievements are evaluated in key subject spheres: Mathematics, the English language, Geography, History, Information and Communication Technology, etc.

In Chile the results SIMCE of national monitoring are used to follow up the indices of education quality. The data are discussed by community. It helps work out a measure system directed at increasing the quality of work of educational institutions. A more detailed examination of data's monitoring shows that as well as in the Russian Federation average marks, results in dynamics and their distribution according to the levels of achievements are denoted by obligatory components. It allows the educational institutions to make analysis of marks' results, to plan necessary methodical work and to prepare a school plan to increase the quality of education (Agencia de Calidad de la Educaciónhttp, 2018).

The analysis of foreign experience shows that analogous forms of the FEM such as test, essay, homework, project, etc. are used to evaluate the level of educational achievements.

In such a way the purpose of the research is working out an optimization model of distribution the FEM when forming regulative, cognitive, personal and communicative UTA for different subjects.

The object of the research is a process of distribution the FEM in educational institutions.

The subject of the research is an optimization model of distribution the FEM when forming the UTA for different subjects.

Thus, we can suppose that the FEM will be formed optimally if a model of optimal planning is used when distributing it.

In accordance with the described above apparatus of the research the following tasks have been set:

- to analyze the content of corresponding literature and normative documents connected with forming the FEM and 
the UTA;

- $\quad$ to realize a selection of methods to build an optimization model;

- $\quad$ to determine a maximum possible set of evaluative means according to the requirements of the FSES;

- $\quad$ to work out forms of evaluation of the degree of helpfulness of each evaluative means when forming this or that type of the UTA;

- $\quad$ to develop an optimization model of distribution the FEM when forming the UTA for different subjects;

- to carry out an approbation of developed materials on the example of the course "Information Sciences and ICT" (the $5^{\text {th }}$ grade).

\section{Materials and Methods}

The following methods are used in the research: method of questioning, working expert evaluations based on coefficients of a rank correlation, method of production function based on a model of optimal planning.

Methods of questioning of the pedagogical research are written or oral, immediate or mediate addresses of a researcher to respondents with various questions where the content of answers on them reveals separate sides of the problem under study. This method is used when people - direct participants of the studied processes and phenomena become a source of necessary information. A questionnaire (a widely used method of questioning) is used in the research.

A questionnaire is an empiric method of the research based on the questioning of a considerable number of respondents. It is used to get information about typical nature of various psychological and pedagogical phenomena.

An expert method is a complex of logical and mathematical procedures that are directed at receiving information, its analysis and generalization in order to prepare and to make a competent and management decision.

The essence of the method is in that experts make analysis of a problem by quantitative and numerical evaluation of opinions and by formal working of results of individual expert evaluations.

The method of expert evaluations gives an opportunity to analyze complex pedagogical processes, phenomena and situations that characterized mainly by quantitative not numerical features (it makes their analysis and evaluation complicated) (Beshelev \& Gurvich, 1980; Novgorodtsevaet al., 2018; Novgorodtseva, et al., 2018). The control of ranks' co-ordination is determined by calculating of a coefficient of rank correlation and a coefficient of concordance

Originally, the theory of production functions was developed in the framework of neoclassical economy. One of the types of production functions is a model of optimal planning which is a system of variables and restrictions that set a great number of possible variants of planningas well as objective function with the help of which an optimal variant of planning is chosen (Kleiper, 2016).

The research was realized in several stages:

1. Building an optimal model of distribution the FEM at the example of the UTA.

2. Establishing materials to carry out an approbation of an optimization model.

3. Carrying out approbation.

4. Interpretation of received results.

5. Creating a generalized model of forming an optimal structure of the FEM for all kinds of the UTA.

The plan of approbation supposes the following:

1. Choosing a discipline.

2. Choosing an expert group.

3. Determining a level of experts' competence by filling lists of self-appraisal used during teachers' certification at educational institutions (table 1). 
Table 1. The list of experts' self-appraisal who participate in selection into an expert group

\begin{tabular}{|c|c|c|c|c|c|c|}
\hline No & Mark & 1 & 2 & 3 & 4 & 5 \\
\hline & Statement & & & & & \\
\hline 1 & 2 & 3 & 4 & 5 & 6 & 7 \\
\hline \multicolumn{7}{|c|}{ General culture } \\
\hline 1 & I have broad outlook, easily keep up conversation on different subjects & & & & & \\
\hline 2 & My behavior and appearance correspond with ethical standards & & & & & \\
\hline 3 & $\begin{array}{l}\text { I am always well informed about main events and changes in modern social } \\
\text { life }\end{array}$ & & & & & \\
\hline 4 & I am tactful in communication. I have a pedagogical tact & & & & & \\
\hline 5 & $\begin{array}{l}\text { I make my statements correctly and easily understood. I have a high standard } \\
\text { of speech }\end{array}$ & & & & & \\
\hline
\end{tabular}

\section{Self-organization}

6 I can organize students' work and my work to reach set goals at the lesson

7 I react constructively on difficulties and mistakes that appear in the process of pedagogical activity

8 I organize my work place well

9 I keep self-control even in situations of high emotional stress

10 I correct a lesson's plan immediately depending on the situation

Goals and tasks setting taking into account age and individual peculiarities of students

11 I set goals and tasks according to age peculiarities of students

12 I correct goals and tasks of activity at the lesson depending on the readiness of students to cope with the material

13 I set goals and tasks of the lesson according to individual peculiarities of students

14 I know and take into account the level of training and development of students while setting goals and tasks of the lesson

Competence in the sphere of motivation the training activity

15 I organize the activity at the lesson taking into account the level of development the training motivation

16 I have a rich volume of materials and tasks that will stimulate an interestamong studentsto different topics of the taught subject

17 I always use information according to interests and needs of students at teaching

Teaching competence

18 I know the taught subject very well

19 The teaching program on my subject is built taking into consideration meta-subject connections

20 My students have high results on the taught subject

Competence in the sphere of development the teaching program and solving pedagogical tasks

21 I know the main normative documents that regulate content and results of training activity on the subject

22 I choose textbooks andtraining aids on the taught subject seriously

23 My teaching program is composed taking into account regulatory 
requirements, material's learning rate, continuity, etc.

Competence in the sphere of organizing the training activity

24 I can organize students to achieve planned goals of the training activity

25 I can organize students to search for additional information that is needed in the process of learning

26 I use methods that induce students to discuss on their own

27 I take into account age and individual peculiarities of students when marking the results of their work

28 I use various methods to mark students

4. Forming an expert group. The task of the expert group was to evaluate each kind of work from the point of view of the helpfulness of using this type of work when forming a concrete component of each kind of the UTA. The set of evaluative means offered by the expert group was formed on the results of the survey of teachers and on materials of the web-site "Dnevnik.ru". This web-site is a creator of a united e-educational sphere for each participants of the educational process. The following kinds of evaluative means with corresponding codes to them are given lower (table 2):

Table 2. Kinds of evaluative means and their codes

\begin{tabular}{ll}
\hline Code & Kind of work \\
\hline 1 & 2 \\
AK/R & Administrative Examination \\
AD & ArithmeticalDictation \\
AUD & Listening Comprehension \\
VKR & Entrance Examination \\
VKD & Entrance Dictation \\
DR & GraduationQualification Work \\
GOVOR & Speaking \\
GIA & StateFinalCertification \\
GZ & Grammar Exercise \\
D/S & Diagnostic Check \\
DIAL & Dialog \\
D & Dictation \\
DU & On-lineDistanceLesson \\
DOC & Report \\
D/R & Homework \\
Zcht & Test \\
I & Exposition \\
ISP & Exposition on the self-composed plan \\
I/S & Exposition with composition \\
IPr & Individual Project \\
IK/R & Final Examination \\
IKD & Final Dictation \\
KPr & Collective Project \\
K-um & Colloquium \\
KKR & Comprehensive Examination \\
\hline &
\end{tabular}




\begin{tabular}{|c|c|}
\hline KAT & Comprehensive Analysis of Text \\
\hline KONS & Tutorial \\
\hline $\mathrm{K} / \mathrm{R}$ & Test \\
\hline KS & Test Copying \\
\hline $\mathrm{KD}$ & Test Dictation \\
\hline KORR & Corrected \\
\hline КР & TermPaper \\
\hline $\mathrm{L} / \mathrm{R}$ & LaboratoryWork \\
\hline LZ & LaboratoryLesson \\
\hline LEK & Lecture \\
\hline $\mathrm{M} / \mathrm{D}$ & Mathematical Dictation \\
\hline $\mathrm{MZ}$ & Modular Examination \\
\hline MIUD & Monitoring of IndividualLearning Achievements \\
\hline $\mathrm{N} / \mathrm{Z}$ & Weekly Task \\
\hline $\mathrm{OZ}$ & RevisionLesson \\
\hline OI & Educational Presentation \\
\hline OIKP & Educational Presentation by Collectively Composed Plan \\
\hline OS & Educational Composition \\
\hline $\mathrm{O}$ & Oral Test \\
\hline OR & Spelling Work \\
\hline OT & Protection of Labour \\
\hline $\mathrm{PZ}$ & Retelling \\
\hline PIS & Writing \\
\hline $\mathrm{P} / \mathrm{P}$ & Memory Writing \\
\hline US & MentalArithmetic \\
\hline $\mathrm{P}$ & Portfolio \\
\hline $\mathrm{P} / \mathrm{R}$ & Practical Work \\
\hline PrZ & Practical Lesson \\
\hline PR & Test Work \\
\hline PrZd & Productive Tasks \\
\hline Pr-t & Project \\
\hline PA & Intermediate Certification \\
\hline $\mathrm{TCh}$ & ReadingTechnique \\
\hline RNO & CorrectingMistakes \\
\hline $\mathrm{K} / \mathrm{K}$ & WorkwithContourMaps \\
\hline RST & Work with Tables \\
\hline $\mathrm{R} / \mathrm{T}$ & Workbook (Summary) \\
\hline REF & Report \\
\hline $\mathrm{S} / \mathrm{R}$ & IndependentWork \\
\hline SEM & Seminar \\
\hline SD & SpellingDictation \\
\hline
\end{tabular}




\begin{tabular}{ll}
\hline SOCh & Composition \\
SK & Picture Composition \\
SPIS & Copyingoff \\
TR & Creative Work \\
Test & Test \\
UR & Lesson \\
U/I & Oral Presentation \\
U/S & Oral Composition \\
FV & ElectiveCourse \\
ChIT & Reading \\
ChT/V & Oral Reading \\
ChT/M & SilentReading \\
EKS & Excursion \\
Ya/T & Language Theme \\
\hline
\end{tabular}

\section{Expert procedure:}

- Forming the maximum possible set of evaluative means that is advantageous to use in the framework of a concrete subject. Based on this set (table 2) and on the survey of teachers the choice of kinds of work (n) is realized by experts. These kinds of work are appropriate to study the discipline from experts' professional point of view.

- Evaluating each kind of work from the degree of helpfulness of using this evaluative means when forming a concrete component of each kind of the UTA. The mark is given from 0 to 100 per cent according to the expert's opinion. These tables are worked out based on the FSES (tables 3-6).

Table 3. The degree of helpfulness of the EM when forming cognitive UTA

Evaluative means
Group work
Report
Homework
Examination
$\ldots$

Table 4. The degree of helpfulness of the EM when forming regulative UTA

Evaluative means
Eroup work
Report
Homework
Examination
$\ldots$


Table 5. The degree of helpfulness of the EM when forming personal UTA

Evaluative means

Group work

Report

Homework

Examination

Table 6. The degree of helpfulness of the EM when forming communicative UTA

\begin{tabular}{lll} 
Components UTA & Questions setting Conflict resolution \\
Evaluative means & Planning & \\
\hline
\end{tabular}

Group work

Report

Homework

Examination

\section{Results}

A new means of educational process was worked out as a result of the study. It is a model that allows to form a structure of the FEM in the framework of a concrete educational discipline. The initial data are: the number of hours for classroom and extracurricular lessons, amount of evaluative means that are possible to use in the framework of this discipline and the helpfulness of each evaluative means from the point of view of forming a concrete kind of the UTA.

The optimization model of the FEM's structure has the following type to form a concrete kind of the UTA from possible four:

$F_{i}=\sum_{j=1}^{n} c_{j} x_{i j} \rightarrow \max$,

$y_{i}=\sum_{j=1}^{n} x_{i j} \geq l_{i}$,

$x_{i j}=k_{j}, i=\overline{1,4}$, forregulatedkindoftheEM,

$x_{i j}=m_{j}$, forappropriatekindoftheEM,

$\sum_{j=1}^{t_{j}} x_{i j} \geq V_{i},+-$

$\sum_{j=1}^{n} x_{i j} t_{j} \leq T_{i}$

$x_{i j} \geq 0$, integers,

where $i$ - a concrete kind of the UTA, $i=\overline{1,4} ; n-$ a total amount of the evaluative means used to form each kind of the UTA;

$x_{\mathrm{ij}}$ - a number of evaluative means of j's type that formi's type of the UTA, $i=\overline{1,4}, j=\overline{1, n}$;

$c_{j-}$ weight that characterizes the helpfulness of the use of j's EM when forming i's type of the UTA, $j=\overline{1, n}$;

$y_{i}-$ a number of EM that take part in forming i's type of the UTA, $i=\overline{1,4}$;

$l$ - a number of kinds of EM determined by a teacher himself taking into account the specificity of a subject;

$k_{j}-$ a number of EM ofj's type regulated by working program of a subject;

$m_{j}-$ a number of EM of $\mathrm{j}$ 's type from the point of view of practicability to use them in the framework of a certain subject; 
$V_{i}$ - a number of EM of creative character defined by experts;

$t_{j}$ - time required to fulfill j's type of work;

$T_{i}$ - total time for classroom and extracurricular study.

According to the results of the research the generalized model to form an optimal structure of the FEM for all kinds of the UTA is offered.

The model has the following form:

$F=\sum_{i=1}^{4} \sum_{j=1}^{n} c_{i j} x_{i j} \rightarrow \max$,

$y=\sum_{i=1}^{4} \sum_{j=1}^{n} x_{i j} \geq l, i=\overline{1,4}$,

$x_{i j}=k_{j}, i=\overline{1,4}$, forregulatedkindoftheEM,

$x_{i j}=m_{j}, i=\overline{1,4}$, forappropriatekindof theEM,

$\sum_{i=1}^{4} \sum_{j=1}^{t_{j}} x_{i j} \geq V$

$\sum_{i=1}^{4} \sum_{j=1}^{n} x_{i j} t_{j} \leq T$,

$x_{i j} \geq 0$, integers where

$n-$ a total number of EM used to form each kind of the UTA;

$x_{\mathrm{ij}}$ - a number of EM of $\mathrm{j}$ 's type that form i's kind of the UTA, $i=\overline{1,4}, j=\overline{1, n}$;

$c_{i j-}$ weight that characterizes the helpfulness of using the j's EM to form i's kind of the UTA, $j=\overline{1, n}$;

$y$-a number of EM that take part in forming the UTA;

$l$ - a number of type of EM determined by a teacher himself taking into account the specificity of a subject;

$k_{j}-$ a number of EM of j's type regulated by working program of a subject;

$m_{j}$ - a number of EM of $\mathrm{j}$ 's type from the point of view of practicability to use them in the framework of a certain subject;

$V$-a number of EM of creative character defined by experts;

$\mathrm{t} \mathrm{j}$ - time required to fulfill j's type of work;

$\mathrm{Ti}$ - total time for classroom and extracurricular study.

\section{Discussion}

The optimization model was approved on the example of forming the cognitive UTA when studying the course "Information Sciences and ICT" (the $5^{\text {th }}$ grade).

Taking into account the age group of students the initial data are: time required to classroom lessons on the subject (T) - 1400 minutes (35 hours), time required to do homework - 700 minutes (according to the Sanitary Standards 2.4.2.2821-10).

The expert group is formed from teachers of Information Sciences of general educational institutions of Angarsk, Irkutsk region. The level of specialists' competences was determined by filling a list of self-appraisal that was worked out based on lists of self-appraisal used during certification of teachers of educational institutions.

According to the processing of 30 lists of self-appraisal an expert group was formed from 10 people. It is about 10 per cent from total amount of teachers of Information Sciences in Angarsk.

The task of the expert group was to evaluate each kind of work from the point of view of helpfulness of using the type of work when forming a concrete component of each kind of the UTA.

The forming of the initial data to model was carried out in the following way.

Using a survey of experts:

- a maximum possible set of evaluative means is organized. It is advantageous to use it in the framework of the subject "Information Sciences and ICT". Eighteen kinds of tasks were included in the set: group work, report, homework, task, problem, tests, individual project, final examination, collective project, examination, laboratory work, lecture, oral test, practical work, paper, independent work, communication, test;

- marks were received from each kind of tasks from the point of view of helpfulness of using this EM when forming 
a concrete component of each kind of the UTA. The range of marking is from 0 to 100 per cent.

According to the working program the following kinds of tasks are obligatory $\left(k_{j}\right)$ : final examination -1 (per year), examination -4 (per each academic term), homework - 30 (per each lesson except examinations), laboratory work 10. Other restrictions are introduced by members of the expert group who are competent in this sphere.

Based on the survey made by experts the following matrix of weighting coefficients $\left(c_{j}\right)$ for all kinds of tasks is built (table 7):

Table 7. Matrix of weighting coefficients of evaluative means

\begin{tabular}{llllll}
\hline Group work & Report & Homework & Task & Problem & Test \\
\hline 0,077 & 0,070 & 0,078 & 0,069 & 0,071 & 0,052
\end{tabular}

Additional restrictions were introduced by experts: number of evaluative means needed to form cognitive UTA $\left(x_{\mathrm{ij}}\right) \geq$ $\frac{2}{3} n(\mathrm{n}=18)$, number of creative tasks $(\mathrm{V}) \geq 3$, number of tests $\left(m_{j}\right) \geq 4$, number of surveys $\left(m_{j}\right) \leq 30$, ratio of tasks' number to the total number of evaluative means $\leq 1 / 3$, approximate time required to fulfill j's type of tasks $\left(t_{j}\right)$, ratio of number of a set of tasks (mainly with the smallest index of time of fulfillment) to the total number of tasks.

The experts also set approximate time spent to fulfill j's kind of task $\left(t_{j}\right)($ table 8$)$ :

Table 8 . Time spending to fulfill concrete types of tasks

\begin{tabular}{ll}
\hline Evaluative means (a kind of task) & Time of fulfillment (minutes) \\
\hline Task & 15 \\
Report & 300 \\
Collective project & 600 \\
Homework & 20 \\
Test & 40 \\
Group work & 20 \\
Problem & 7 \\
Laboratory work & 25 \\
Practical work & 25 \\
Lecture & 15 \\
Independent work & 25 \\
Examination & 35 \\
Communication & 240 \\
Paper & 360 \\
Test & 20 \\
Individual project & 600 \\
Survey & 7 \\
Final examination & 35 \\
\hline
\end{tabular}

A restriction to the number's ratio of some tasks (mainly with the smallest index of time of fulfillment) was additionally introduced to the total amount of tasks in order the building of a model was not based only on the evaluative means.

While approbation of the model the following results were received (picture 1): 
Picture 1. Results of approbation of the optimization model

\begin{tabular}{lllll}
\hline Evaluative means & Number & Kind & $\begin{array}{l}\text { Time required to fulfill one kind of } \\
\text { task (minutes) }\end{array}$ & Total time (minutes) \\
\hline Task & 29 & 1 & 15 & 429,1337798 \\
Report & 0 & 1 & 300 & 100,0012 \\
Collective project & 0 & 0 & 600 & $-0,0006$ \\
Homework & 30 & 1 & 20 & 600 \\
Test & 0 & 0 & 40 & 0 \\
Group work & 11 & 1 & 20 & 212,2302087 \\
Problem & 36 & 1 & 7 & 250,877655 \\
Laboratory work & 10 & 1 & 25 & 250 \\
Practical work & 18 & 1 & 25 & 455,594388 \\
Lecture & 2 & 1 & 15 & 37,16396851 \\
Independent work & 0 & 0 & 25 & 0 \\
Examination & 4 & 1 & 35 & 140 \\
Communication & 0 & 0 & 240 & 0 \\
Paper & 0 & 0 & 360 & 0 \\
Test & 4 & 1 & 20 & 80 \\
Individual project & 0 & 0 & 600 & $-0,0006$ \\
Survey & 30 & 1 & 7 & 210 \\
Final examination & 1 & 1 & 35 & 35 \\
Restriction ona kind & & 12 & & 2100 \\
Restrictions on time for a & & & & 700 \\
lesson & & & & \\
Restrictions on time for & & & & \\
extracurricular & & & & \\
Restrictions on number of & & & & \\
creative tasks & & & & \\
As & & & & \\
\hline
\end{tabular}

As a result of modeling the following structure of the FEM was received: number of tasks -29 , homework - 30, group work -11 , tasks -36 , laboratory works -10 , practical works -18 , lectures -2 , examinations -4 , tests -4 , surveys 30 , final examination -1 .

\section{Conclusion}

The forming of the UTA among students is one of the tasks of modern system of education. In its term the development of ways to form the UTA and evaluation of their organization becomes a foreground task for teachers of general educational institutions. The analysis of literature on the problem under study revealed the presence of materials of recommended and unformalized character (Myasnikova, 2016; Ogneva, 2017). The questions of structure and number of evaluative means are taken by educational institutions themselves as a rule. They are based on teachers' experience and intuition and it is not always effective.

One of the approaches to work out a well-founded structure of a set of evaluative means to form the UTA among students based on the optimization model is offered in this paper.

As a result of the research the following tasks are solved: the FEM is assigned based on the experts' marksto develop cognitive UTA on the example of the course "Information Sciences and ICT" (the $5^{\text {th }}$ grade); the optimization model is offeredto distribute the FEM when forming the UTA for different subjects; the approbation of the distribution model of the FEM is realized on the example of the course "Information Sciences and ICT".

The following problem is also revealed: it is complicated to realize to the full extent the use of different creative kinds 
of tasks having such a number of hours given to a subject. That is why only one type of creative task entered into the optimal set of EMwhen calculating. It is a group work because it is the least time consuming

The information received by using the developed optimization model can be considered when building working programs and forming a well-founded fund of evaluative means.

\section{References}

Agencia de Calidad de la Educaciónhttp://www. simce.cl/ (accessed: 12.02.2018).

Asmolov, A. G., Burmenskaya, G. V., \& Volodarskaya, I. A. (Eds) (2011). Forming the universal educational actions in middle school: from action to a thought, System of knowledge. Moscow. ProsvescheniePubl, 156.

Beshelev, S. D., \& Gurvich, F. G. (Eds) (1980). Mathematical and statistical methods of experts' evaluations. Moscow. StatisticsPubl, 161.

Kleiper, G. B. (Ed) (2016). Economics. Modeling. Mathematics. Selected works. Russian Academy of Sciences. The Central Economics and Mathematics Institute. Moscow. CEMI RAS Publ. 856.

My School http://www.myschool.edu.au/(accessed: 12.02.2018).

Myasnikova, O. V. (2016). Means of optimization the process of education. Scientific and Methodic e-journal "Concept", 15, 1091-1095.

National Center for Education Statistics in the sphere of education. http:// nces.ed.gov(accessed: 12.02.2018).

Novgorodtseva, T. Yu., Ivanova, E. N., Lesnikov, I. N., \& Rodionov, A. V. (Eds) (2018). Technology of using methods of statistical processing of experts' evaluations to solve relevant tasks of educational process. Modern high tech, 6, 123-128. https://doi.org/10.17513/snt.37044

Novgorodtseva, T. Yu., Rodionov, A. V., Dyadkin, Yu. A., Pegasova, N. A., Ivanova, E. N., Lesnikov, I. N., \& Nikiforova, I. A. (2018). Finding out priority kinds to organize a student's independent work and types of tasks of the independent work in classroom based on methods of experts' evaluations. Management of economic systems, 12.

Ogneva, A. S. (2017). Innovative models of optimization the education based on subjective approach to teaching. Actual problems of humanities and sciences, 4, 169-170.

Pashkevich, A. V. (Ed) (2018). Fundamentals of designing pedagogical technologies. The relationship of theory and practice: study aids. Moscow. INFRAPubl. 194.

The Federal State Educational Standard of basic general education (Laws of the Russian Federation).

The Nation's Report Card: A First Look: 2013 Mathematics and Reading / National Center for Education Statistics; Institute of Education Sciences; U.S. Department of Education // NCES http://nces.ed.gov(accessed: 12.02.2018).

The National Assessment Program http://www.nap.edu.au/(accessed: 12.02.2018). 